\title{
Prestressing Method of Rigid Joints in Multi-storey Steel Frame Mining
}

\author{
Vershinin Dmitriy S. \\ T.F. Gorbachev Kuzbass State Technical University, \\ Kemerovo, Russian Federation \\ dimavershinin1@mail.ru
}

\author{
Dobrachev Valeriy M. \\ Novosibirsk State University of Architecture and \\ Construction (Sibstrin) \\ Novosibirsk, Russian Federation \\ mdk@sibstrin.ru
}

\begin{abstract}
The paper presents a brief overview of the existing solutions for connecting the rigid joints with the steel frame columns in multi-storied buildings, the advantages and disadvantages of the existing designs of rigid connection are analyzed; on the basis of the analysis performed a new structural design of beam to column connection with the use of the high-strength beam and prestressing of the near-support girder segment is suggested. A high-strength tie with pre-stressing creates in a girder opposite torques in the step and span girder zones and is also involved in transfer of the support moment from girder to the column. The paper presents the comparison of the metal consumption for a steel frame containing different longitudinal beam to column joints, the area of application of the new joint structural design has been specified; it was also shown that as the result of using the high-strength tie one may reduce the beam cross-section and reduce the metal consumption per a building frame.
\end{abstract}

Keywords - new structural design, rigid joint, high-strength tie, pre-stressing, flange unit.

\section{INTRODUCTION}

Due to the widespread occurrence of frame systems in multistoried frame constructions reduction of steel consumption in such systems appears to be a topical task. The construction and design practices allowed developing a number of standard structural designs for beam to column joints $[1,2]$ that are being currently used in the steel building frameworks.

By degree of restraint all beam-to-column joints may be divide into hinged (pivot), rigid and semi-rigid ones [3]. The border between hinged and rigid joints and semi-rigid ones is quite conventional. This is due to the fact that in most cases by hinged connection there is some beam locking in the column connection joint and in case of rigid connection - some flexibility. The studies [3-9] are devoted to performance of steel building frames with account for actual bending stiffness of the beam to column connection.

The Russian design regulations $[10,11]$ does not contain the joint classification by the degree of beam locking in a column. At that at the beam to column joints in steel frames it is allowed to use the steel plastic plates for redistribution of bending moments. In the foreign regulations depending on the degree of the beam fixation in a column the joints are divided into ordinary (hinged), rigid and semi-rigid ones [12]. In the foreign regulations the two criteria may be used for joint classification by rigidity: by the joint rotational stiffness that is determined by the bending stiffness of its components; by the results of experimental data, on the basis of experience in prior satisfactory performance and by the results of calculation on the basis of test findings.

The Fig. 1. presents the most common used types of rigid joints. The proposed structural design of the girder connection with the edge column [13-15] is shown in the Fig. 2, the alternative structural design for the middle column $[16,17]$ is shown in the Fig. 3.

The purpose of the current stage of the study is substantiation of performance and applicability of the suggested design solution for connection of beams to pre-stressed columns. In order to achieve the objective the following tasks have been set: 1 . To identify the peculiarities of distribution of inner forces within the framed systems with the suggested method of the unit prestressing; 2. To develop the lump criterion for identification of the area of smart use of the suggested pre-stressing method. 3. To perform trial design of the double-span five-storied frame with the rigid flange unit of beam-to-column connection with the plated unit and suggested unit design. To determine using the iteration method the optimum tie parameters (diameter, length, grade of steel and pre-stressing force). 4. To perform on the basis of trial design the comparison of metal consumption per a steel frame containing different beam-to-column connection units; 5 . To specify the area of smart use of the suggested pre-stressed units.

\section{OBJECT OF STUDY}

The objective of the new structural design [13-17] is increase in the capacity of the rigid flange unit of the girder to column connection. At that high-strength tie is used that usually consists of the two pre-stressed bars. High-strength tie is placed in the support girder zone proximal to the top chord with the eccentricity $e=h_{0}+h_{b} / 2$ against the girder axis. One edge of the tie is fastened to the vertical plate welded to the horizontal column stiffener or to the column flange. Another tie edge is attached to the stop placed at the top beam flange. Tie prestressing is performed with the use of nut with tension force control. At the point of girder bearing on the medium column the tie goes through the holes in the column flanges and is attached to the stops at the girder top flanges. 
a)

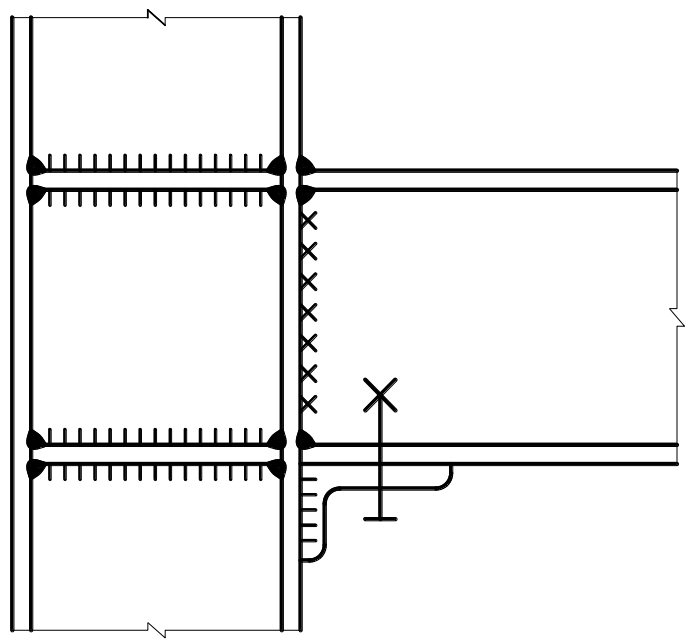

b)

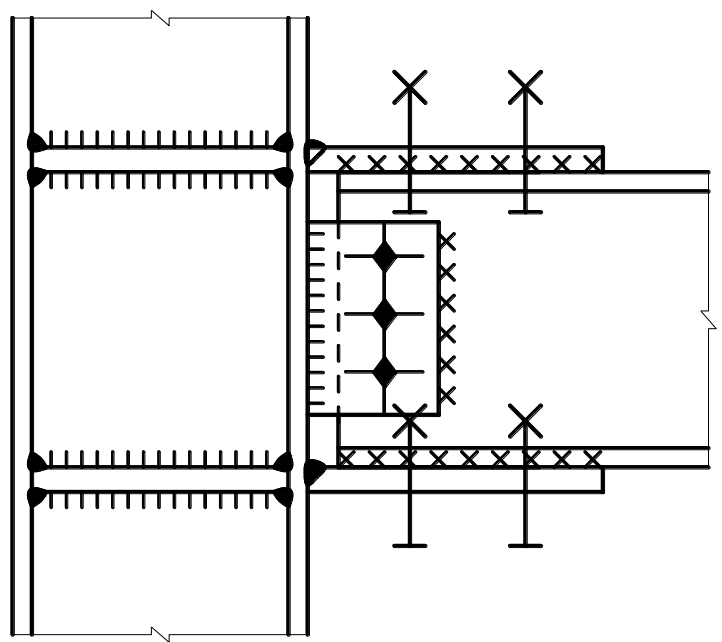

c)

d)

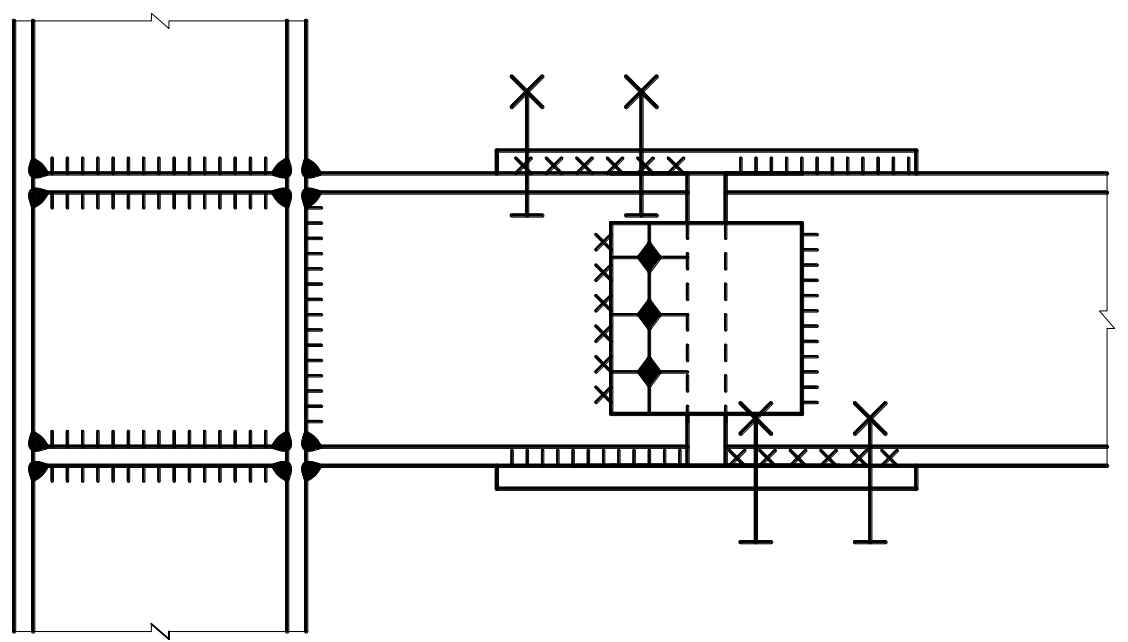

e)

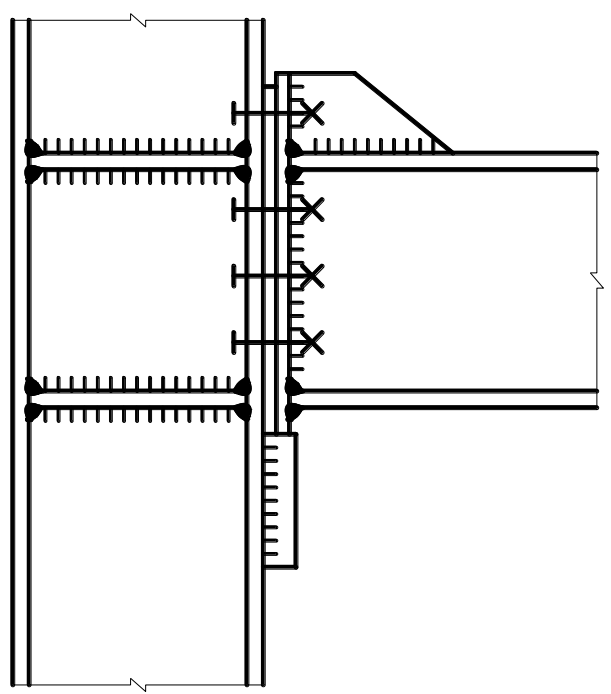

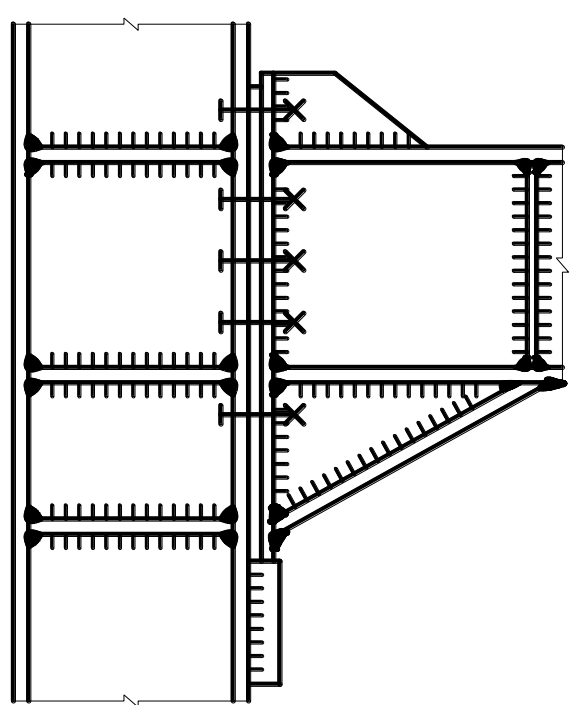

Fig. 1. Rigid joints design

a) butt-welded girder, b) plate assembly,

c) side-mounted joint, d) flange unit, e) haunch reinforcement 


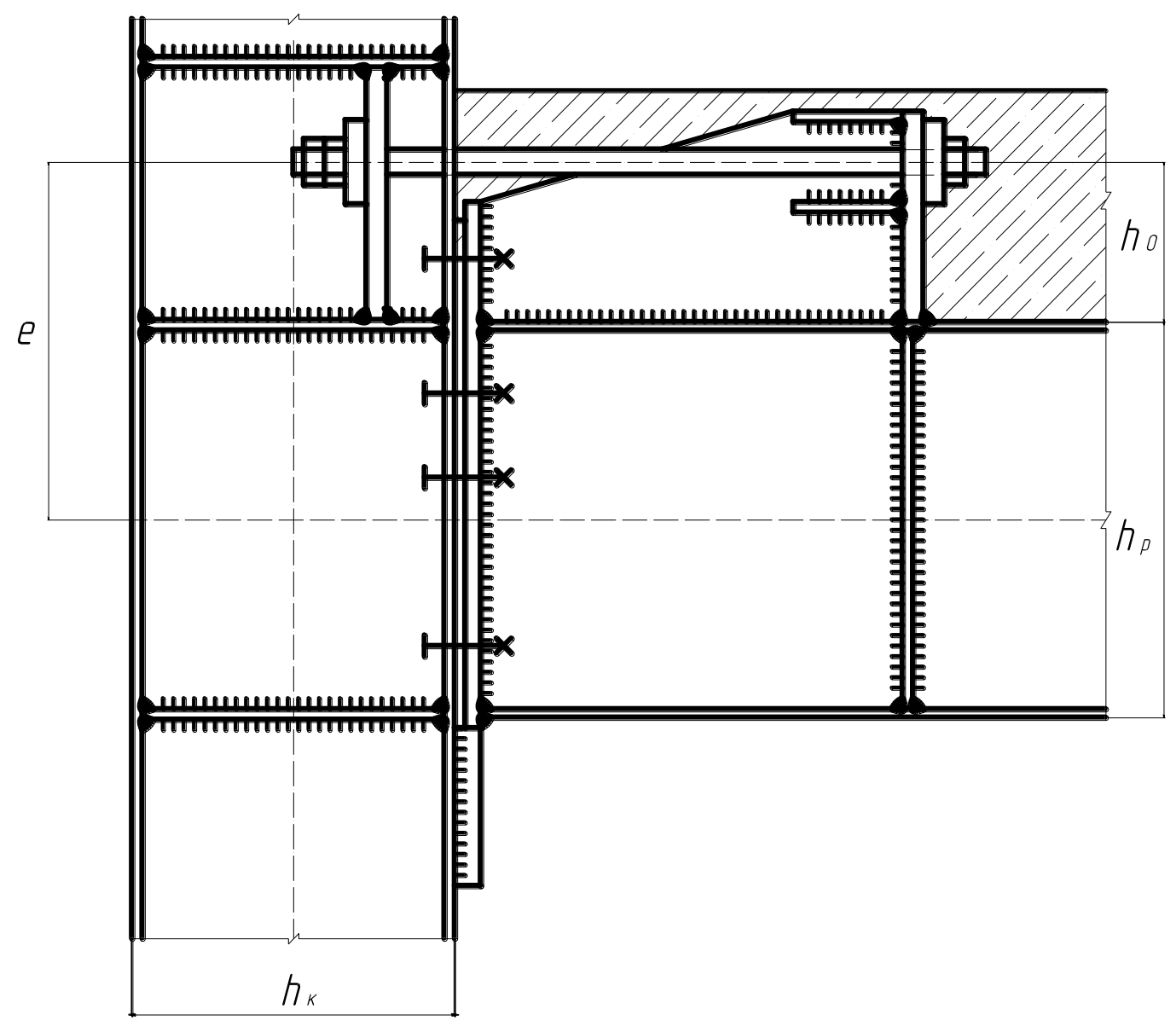

Fig. 2. New structural design of a frame unit

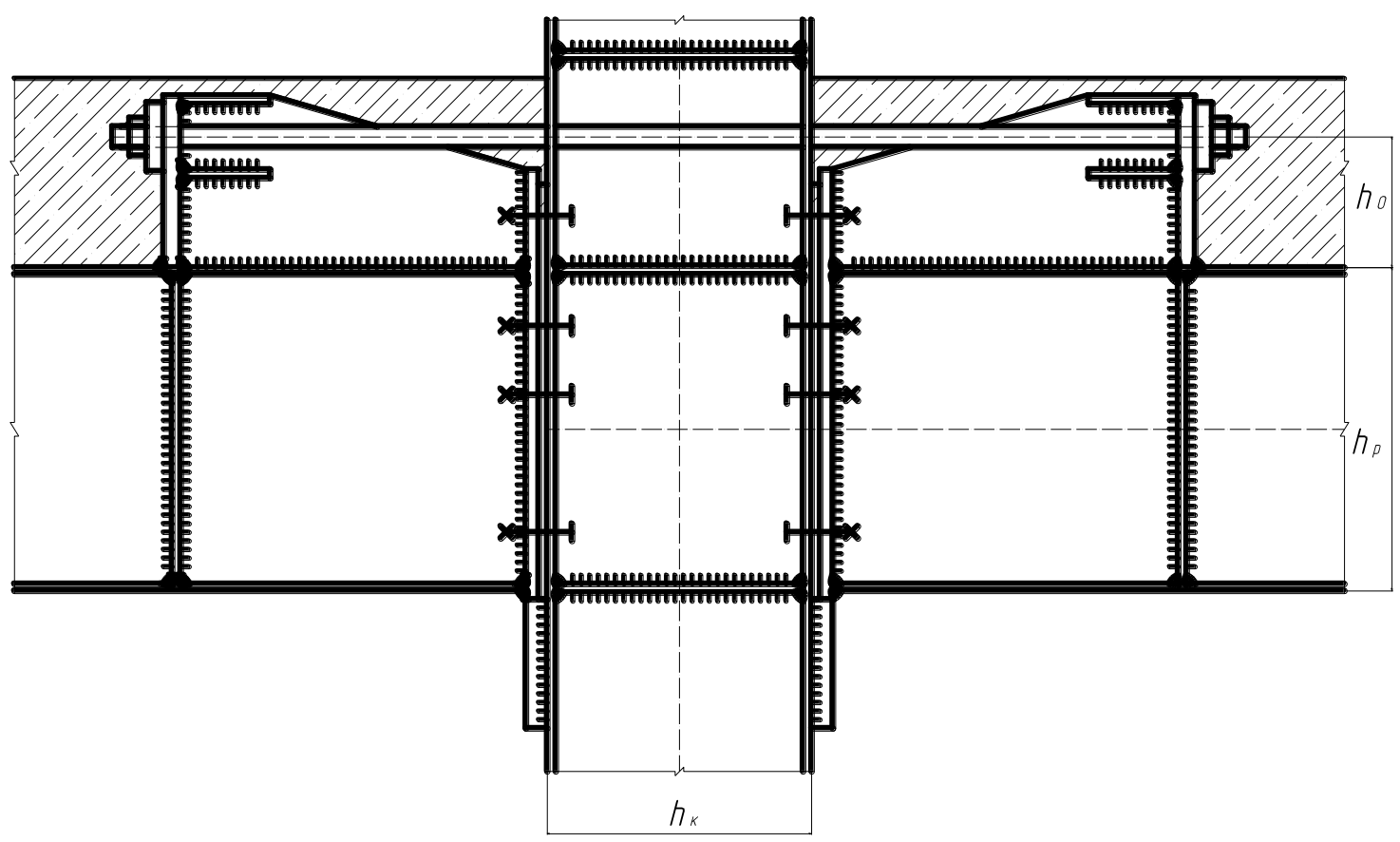

Fig. 3. Alternate unit design with girders supporting on the medium column 
The pre-stressed high-strength tie along with the flange joint participates in the transfer of the bending moment from the girder to column. Besides, as the result of pre-stressing, generates the moment opposite in sign in the support and span beam zones which promotes to more favorable force distribution within the girder. The use of the high-strength tie results in reduction in the required stringer height and reduction in the steel consumption per a building frame. For example, at $\mathrm{h}_{\mathrm{b}}=0.4 \mathrm{~m}, \mathrm{~h}_{0}=0.1 \mathrm{~m}$ and pre-stressing force $\mathrm{N}^{\mathrm{ps}}=0.19 \mathrm{MN}$, the pre-stressing moment $\mathrm{M}^{\mathrm{ps}}=60 \mathrm{KNm}$, for the specified pre-stressing force a tie consisting of one rod with the diameter $18 \mathrm{~mm}$ from steel $40 \mathrm{X}$ or a tie consisting of the two rods with the diameter $14 \mathrm{~mm}$ from steel $40 \mathrm{X}$ may be used.

\section{MATERIALS AND METHODS}

For the determination of the stress-strain state of frame systems with pre-stress the proposed method finite element method was used, that is implemented in software systems Robot and Ansys.

The simplest example of a single-span single-story frame shows the effect of pre-tightening tension in the hard site on the distribution of internal forces in the frame members. In order to identify the features of the forces distribution a series of static frame designs with variation of ratios of the beam and column relative stiffness $0.1 \leq \mathrm{k} \leq 10$, where $\mathrm{k}=\mathrm{i}_{\mathrm{b}} / \mathrm{i}_{\mathrm{c}}=\mathrm{I}_{\mathrm{b}} \mathrm{H} / \mathrm{I}_{\mathrm{c}} \mathrm{L}$ was performed. These ratios have been taken to be the most common for the single-story single-span frames.

The authors performed the design finite-element analysis of the pre-stressing impact on the force distribution in the single-span, double-span and three-span single-story and multi-storied frames. The dependence of ratio of the support and span moments in a girder $\mathrm{M}_{\mathrm{on}} / \mathrm{M}_{\mathrm{mp}}$ on the ratio of relative stiffness $\mathbf{k}$ has been obtained that was compared with the reference figures [18]. It was established that the imprecision does not exceed $3 \%$.

\section{RESULTS AND DISCUSSION}

By analyzing the nature of inner forces distribution within the single-story single-span frame being considered the following may be noted. For a single-story single-span frame $M_{\text {sup }} / M_{\text {sp }}=4 /(3 k+2)$, where $k=i_{b} / i_{c}-$ ratio between relative stiffness of the girder and column. At $\mathrm{k}>0.67$ the support moment becomes less that the span one.

The support and spam moments in a girder produced by pre-stressing are opposite in sign to the relevant girder moments produced by vertical load. Pre-stressing reduces the values of the support and span ultimate bending moments in a girder as well as reduces the difference between them. The ratio of the support and span moments produced by prestressing depends on the ratio between the relative girder and column stiffness $\mathrm{k}$ and lies within the range from $\mathrm{M}_{\text {sup }}^{\mathrm{ps}} / \mathrm{M}_{\text {sp }}^{\mathrm{ps}}=2.1$ at $\mathrm{k}=0.1$ up to $\mathrm{M}_{\text {sup }}^{\mathrm{ps}} / \mathrm{M}_{\text {sp }}^{\mathrm{ps}}=8.1$ at $\mathrm{k}=10$. In the typical [19] of such frames the ratio of relative stiffness lies within the range $0.7<\mathrm{k}<1.5$, the moments ratio for this range is
$3.1<\mathrm{M}_{\text {sup }}^{\mathrm{ps}} / \mathrm{M}_{\text {sp }}^{\mathrm{ps}}<4.3$, i.e. the support moment is always bigger than the span one.

The use of pre-stressing significantly increases the shear in a column between the girder and tie (by the value of the tie pre-stressing) as well as increases the bending moment in a column.

On the basis of results of the example being considered as well as those of analysis of ratios of relative stiffness of typical designs of "Cansk" [19] series the conclusion may be drawn that the use of the suggested pre-stressing method in the structures of single-story single-span buildings can find restricted use only. This is due to the fact that in most cases the ratio between the relative stiffness in such frames $k>0.67$ and $\mathrm{M}_{\text {sup }}<\mathrm{M}_{\text {sp }}, \mathrm{M}_{\text {sup }}^{\mathrm{ps}}>\mathrm{M}_{\mathrm{sp}}^{\mathrm{ps}}$, at such ratios the suggested pre-stressing method does not result in equalization of the ultimate support and span bending moments in a girder with the exception of relatively low frames with a large span (height $4.8 \mathrm{~m}$ and spans of 18, $24 \mathrm{~m}$ ). Such frames are also a challenge in terms of the roof design by placing a tie.

In the actual frames of single-span multi-storied frameworks the ratio of relative stiffness lies within the range of $0.1<\mathrm{k}<0.5$. The specified range $\mathrm{k}$ corresponds to the range of ratio between the support and span moments in a girder produced by the vertical load $1.8<\mathrm{M}_{\text {sup }} / \mathrm{M}_{\mathrm{sp}}<2.0$ and the range of the ratios between the moments in a girder produced by prestressing $2.0<\mathrm{M}_{\text {sup }}^{\mathrm{ps}} / \mathrm{M}_{\mathrm{sp}}^{\mathrm{ps}}<3.0$. This is why it is viable to use the suggested pre-stressing method in such frames as it allows reducing the support and span ultimate bending moments in a girder as well as the difference between them.

In multi-span frames the ratio between the support and span moments in a girder at the medium column $\mathrm{M}_{\text {sup }}^{\text {mid }} / \mathrm{M}_{\mathrm{sp}}>1.5$ at $0.125<\mathrm{k}<8$, and the ratio between the support and span moments in a girder at the edge column makes $\mathrm{M}_{\text {sup }}^{\mathrm{ex}} / \mathrm{M}_{\mathrm{sp}}>1.2$ at $\mathrm{k}<0.5$. In the actual frames $0.1<\mathrm{k}<0.5$. Due to this fact it is worth using the suggested pre-stressing method within the entire range of the relative stiffness ratios.

Along with increase in the building height the support moment in a girder produced by horizontal load is increased. At that the support moment produced by horizontal load features different signs at the girder edges which restrains the area of application of the suggested pre-stressing method in high-rise buildings where the moment produced by horizontal load is comparable to the moment produced by vertical load. For example, for a single-span 15-storied frame with the span of $6 \mathrm{~m}$ and the floor height $3.6 \mathrm{~m}$ upon the vertical load $9.81 \mathrm{kPa}$ and the first wind region the support moment in the second-floor girder produced by vertical load makes 0.17 $\mathrm{MNm}$, that by the wind one $- \pm 0.17 \mathrm{MNm}$. The higher the floor lies the less is the support moment in a girder that is produced by horizontal load. The support moment in a girder produced by horizontal load is reduced with increase in the number of building spans. In case of the similar double-span frame the support moment in a girder produced by wind load decreases twofold. This is why it makes sense to use the suggested pre-stressing method in single-span multi-storied buildings up to 15 floors high, double-span multi-storied 
buildings up to 25 - 30 floors high, in case of three or more spans - up to 50 floors. In higher buildings it makes sense to use the suggested pre-stressing method at the upper layers only.

By the use of the pre-stressing the girder material (upon the constant cross-section) will be used in the most efficient way given that the support and span moments are equal to the design force combination. Taking into consideration that the contribution of stress from horizontal load in the designed combination for the buildings up to $30 \mathrm{~m}$ high is insignificant as well as upon constant girder height the condition upon which the material of the uniform cross-section girder is used in the most efficient way may be expressed as follows:

$$
\frac{\mathrm{M}_{\text {sup }}+\mathrm{M}_{\text {sLp }}^{\mathrm{p}^{5}}}{\mathrm{M}_{\text {sp }}+\mathrm{M}_{\text {sp }}^{\mathrm{p}^{5}}}=1
$$

where $\mathbf{M}_{\text {sup }}, \mathrm{M}_{\text {sp }}$ - support and span moments in a girder produced by vertical load;

$\mathrm{M}_{\text {sup }}^{\mathrm{ps}}, \mathrm{M}_{\mathrm{sp}}^{\mathrm{ps}}-$ support and span moments in a girder produced by pre-stressing.

The support and span moments produced by vertical loading of the girder and pre-stressing may be presented as follows:

$$
\begin{array}{cc}
M_{\text {sup }}=\alpha_{1} M ; & M_{\text {sup }}^{p s}=\alpha_{2} M^{p s} ; \\
M_{\text {sp }}=\beta_{1} M ; & M_{s p}^{p s}=\beta_{2} M^{p s} ; \\
\alpha_{1}+\beta_{1}=1 ; & \alpha_{2}+\beta_{2}=1
\end{array}
$$

where $\alpha_{1}, \beta_{1}, \alpha_{2}, \beta_{2}-$ moment distribution factors depending on the relative stiffness ratio $\mathrm{k}$;
M - span moment produced by vertical load for a singlespan hinged beam, in case of uniformly distributed load $q$ along the beam length $l$, moment $\mathrm{M}=\mathrm{ql}^{2} / 8$, for the load $\mathrm{P}$ applied to the beam middle $-\mathrm{M}=\mathrm{Pl} / 4$;

$\mathrm{M}^{\mathrm{ps}}=\mathrm{N}^{\mathrm{ps}} \mathrm{e}-$ moment for a single-span hinged beam upon pre-stressing with the load $\mathbb{N}^{p s}$.

Taking into account (2) the condition (1) may be written as follows:

$$
\mathrm{f}_{1}=\left(2 \alpha_{1}-1\right)-\left(2 \alpha_{2}-1\right) \frac{M^{D^{s}}}{M}=0
$$

The graphs $f_{1}(k)$ at the parameter values $\gamma=\mathrm{M}^{\mathrm{ps}} / \mathrm{M}$ equal to $0.5,0.6,0.7,0.8,0.9,1.0$, for a single-span singlestorey and single-span two-story frame are shown in the Fig. 4. The graphs are designed based on the series of static frame design with the use of the finite-element method.

By analyzing the graphs of the function $f_{1}(k)$ the following may be noted. For single-span single-storey frames the condition ( 3 ) is fulfilled upon $\mathrm{k}<0.2$, for typicals of the single-storey single-span frames $0.7<\mathrm{k}<1.5$, which means that it doesn't make sense to use the suggested pre-stressing method for single-span single-storey frames. For two-storied single-span frames the condition (3) is fulfilled upon $0.1<\mathrm{k}<0.8$, in actual frames of multi-storied single-span frames the ratio of relative stiffness lies within the range of $0.1<\mathrm{k}<0.5$, thus, it makes sense to use the suggested prestressing method for such frames. With increase in the value of the $\mathrm{k}$ parameter the values of the $\gamma$ parameter is reduced upon which the condition (3) is fulfilled. Therefore, the more
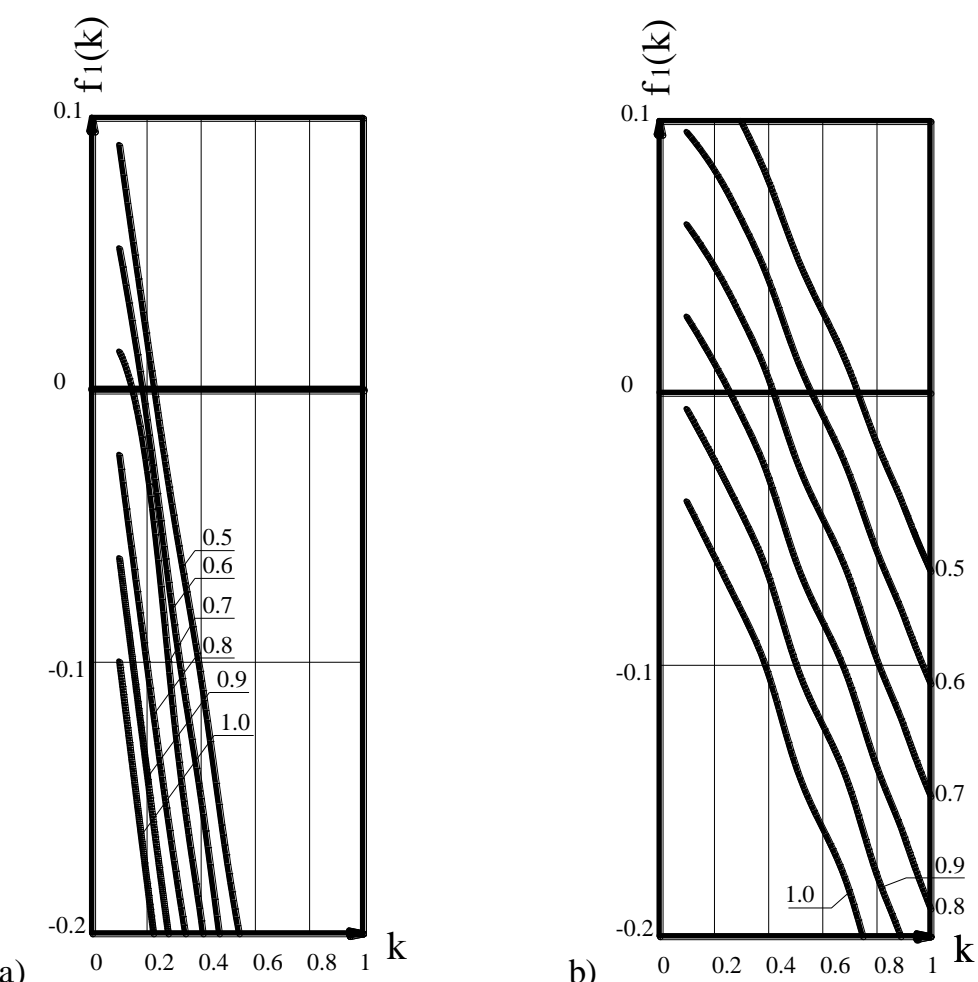

Fig. 4. Graphs of the $f_{1}(k)$ function upon the parameter $\gamma=0.5 \ldots 1.0$, for a

a) single-stiry single-span frane, b) two-story single-span frame 
the relative stiffness ratio $\mathrm{k}$ is the lesser pre-stressing moment $\mathrm{M}^{\mathrm{ps}}$ is required for equalization of the support and span ultimate bending moments in a girder.

For the purposes of comparison of the metal consumption by a steel frame containing different designs of beam-to-

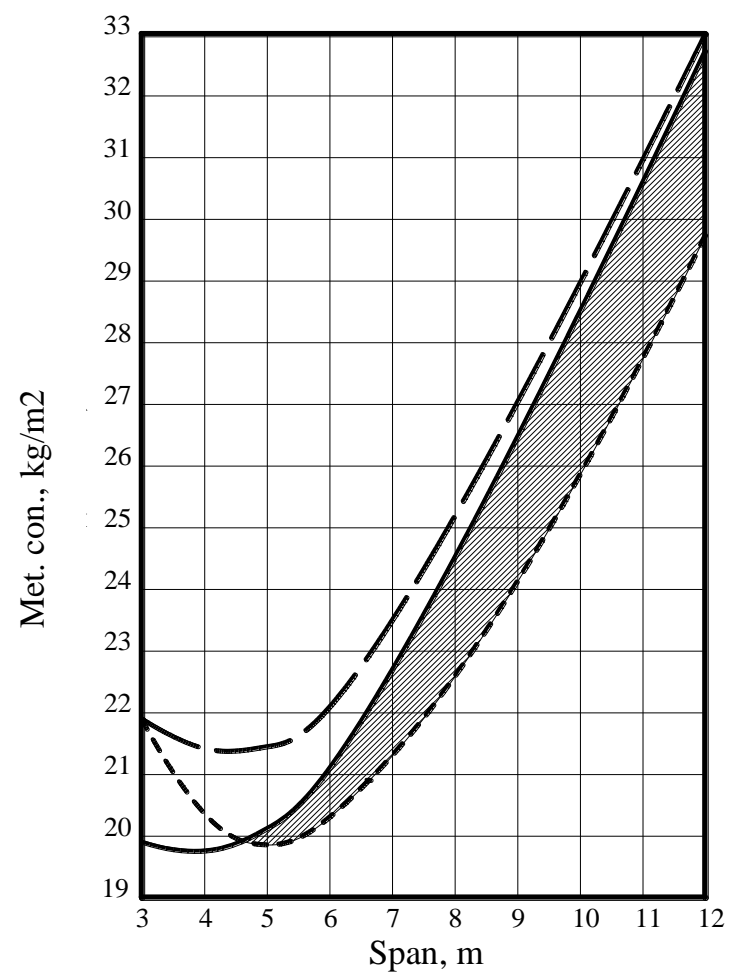

a)

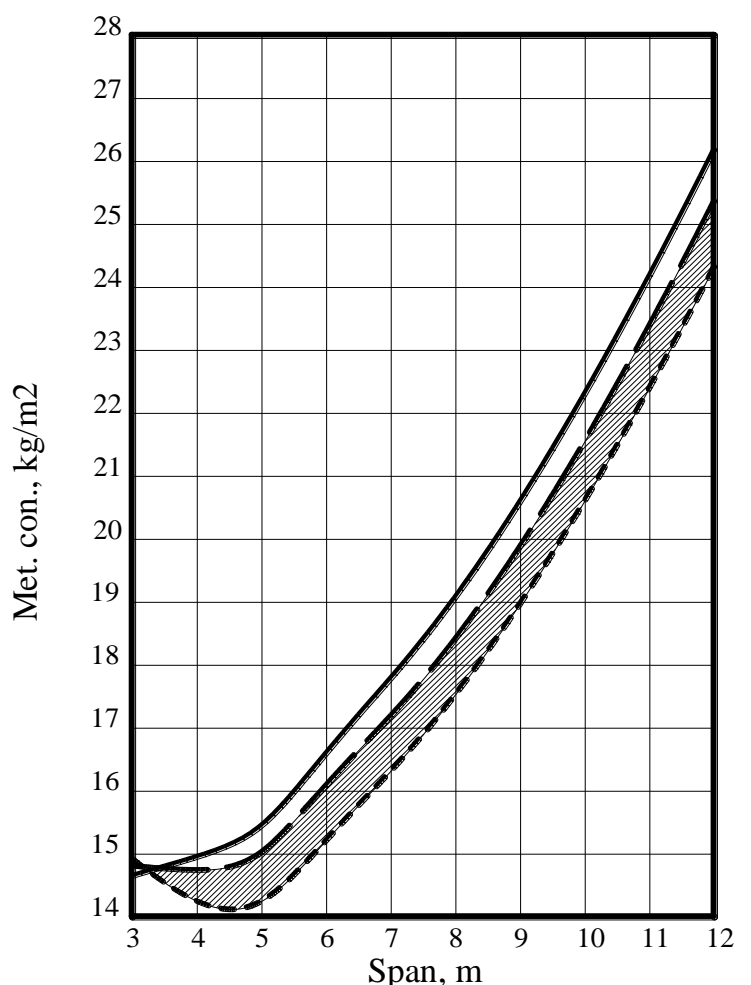

c) column connection assembles a series of static calculations for a double-span five-storied frame using the finite-element method, proportioning of beam and column cross sections as well as designing of the major frame components were performed. Series of static calculations was performed with

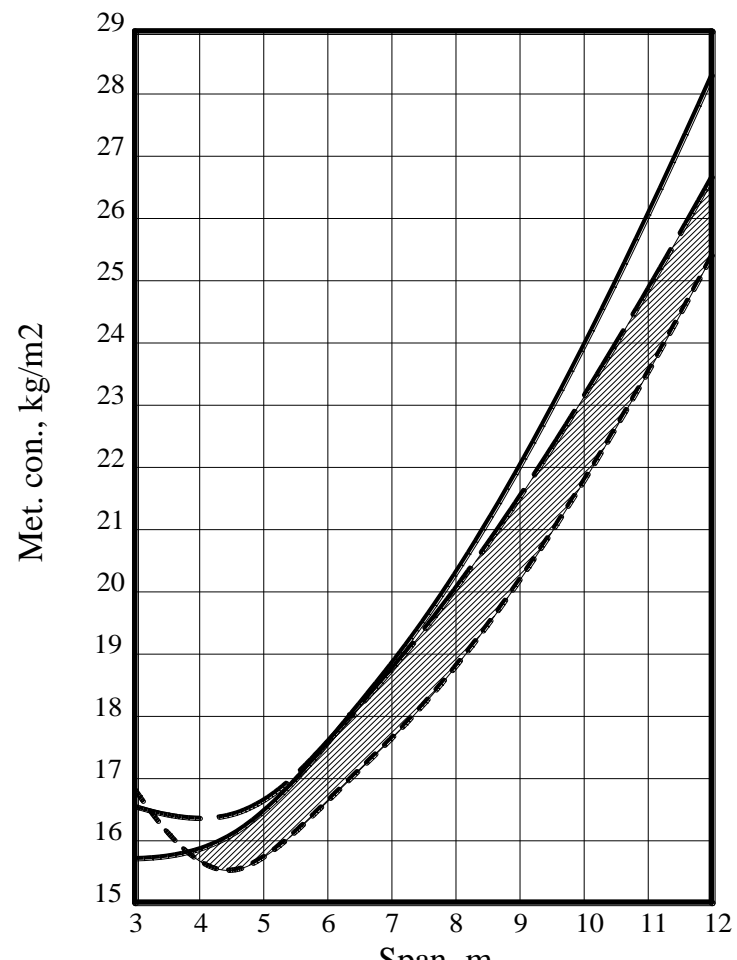

Span, m

b)

Fig. 5. Diagrams of metal consumotion per a building frame upon the connection type and cross beam pitch at the step of transverse frames a) $3 \mathrm{~m}$, b) $6 \mathrm{~m}$, c) $9 \mathrm{~m}$

Unit on plates

Flange unit

Suggested design 
the use of the software packages Robot and Ansys. Divergence of the results of calculation obtained in different software packages does not exceed 5\%. The columns, girders and ties were designed with the use of rod elements; separate loading was produced for pre-stressing simulation. During the calculation the permanent load produced by the steel works and reinforced concrete floor weight, design effective load (assumed equal to $3.92 \mathrm{kPa}$ ), snow load on the IV snow region and wind pressure for the type of locality B corresponding to the III wind region were taken into account. The floor height was assumed to be equal to $3.6 \mathrm{~m}$, span buildings was assumed to be $3,4,5,6,9$ and $12 \mathrm{~m}$, the pitch of cross frames was assumed to be equal to $3,4,5,6,7,8,9 \mathrm{~m}$.

By trial design the 3 designs of the beam-to-column connection were accepted - girders with the rigid connection unit (conventional unit with covers (Fig. 1, b), flange rigid unit (Fig. 1, d)) and the suggested structural design - girders with pre-stressed ties (Fig. 2, 3). The pre-stressing force was selected according to the condition (3) as well as condition $\mathrm{M}_{\text {sup }}^{\mathrm{ps}} \leq \mathrm{M}_{\text {calc }}$, where $\mathrm{M}_{\text {calc }}$ is the support moment in a girder produced by the design combination of forces inclusive of all loads. The condition $\mathrm{M}_{\text {sup }}^{\mathrm{ps}} \leq \mathrm{M}_{\text {calc }}$ was achieved by means of a few structural iterations and changes in the pre-stressing parameters (the tie length, its cross section, pre-stressing force and the distance between the girder and tie axes e). The graphs of the function $\mathrm{f}_{1}(\mathrm{k})$ (Fig. 4) were used for estimation of the optimum tie prestressing force. By proportioning of the girders, ties and columns cross sections the design combinations of loads for both stages: assembly erection and assembly operation stages were used. During the assembly erection stage the design load combinations included load produced by dead weight and pre-stressing. During the assembly operation stage all loads were taken into account in the design load combinations. The necessity of fulfillment of the additional condition $\mathrm{M}_{\text {sup }}^{\mathrm{ps}} \leq \mathrm{M}_{\text {calc }}$ is substantiated by the fact that for the erection stage the determining moment is $\mathrm{M}_{\text {sup }}^{\mathrm{ps}}$ and the girder cross section is selected according to the support moment of pre-stressing, if $\mathrm{M}_{\text {sup }}^{\mathrm{ps}}>\mathrm{M}_{\text {calc }}$, then the required girder and tie cross sections will be bigger than at $M_{\text {sup }}^{p s} \leq M_{\text {calc }}$.

By proportioning of girders and columns the C245 steel was used, for girder flanges - C345. The ties were assumed to be made of the high-strength steel 40X, the tie diameter assumed to equal to from 16 up to $36 \mathrm{~mm}$. By proportioning and validation of girder and column cross sections all the required inspections have been performed according to the SNiP II-23-81*. By flange inspection all necessary tests were performed according to [20]. By proportioning of column cross sections additional tests of the wall strength and stability at the points of girder attachment and tie placement as well as those of column flange strength at the point of the tie anchoring with allowance for the local bending caused by tie pre-stressing were performed. In cases when the column flange didn't meet the specified requirements it was reinforced by a diagonal stiffening rib and if necessary the thickness of the column flange was increased locally.

The Fig. 5 presents the diagrams of metal consumption per a building frame. By analysis of the frame design figures the following conclusions may be drawn.
The ultimate bending moment in the support and span girder zones in case of using tie pre-stressing is reduced by $2-2.3$ times as compared to conventional solutions. The stress-strain state of the edge columns upon pre-stressing is deteriorated. Firstly, within the span between the girder and tie the shear force is increased by $(0.5-0.6) \mathrm{N}^{\mathrm{ps}}$. Secondly, by tie fixing to the column flange the column flange shall be tested with allowance for the local bending caused by tie pre-stressing, in most cases local flange thickening is required. Thirdly, the moments in columns produced by pre-stressing increase the ultimate bending moment at the section between the tie and girder. Moment increment shall be taken into account by testing the column strength and its stability within the frame plane, by testing the column stability from the frame plane the ultimate bending moment in the medium third of the column length is changed insignificantly.

Pre-stressing does not deteriorate the stress-strain state of the medium columns; therefore, the efficiency of this method increases in multi-span buildings.

Qualificative tests by proportioning of the girder cross sections: testing the normal stress in the support and span cross sections as well as testing the reduced stress in the support cross section area. The Qualificative tests by proportioning of the column cross sections were the stability tests in and out of the frame plane.

As the result of detailed calculation and designing of the major units the structural coefficients presented in the Table 1 were obtained. For the suggested design the highest value of the structural factor was obtained due to accounting of the tie weight as well as weight of additional components for tie fixing to the girder and column. Metal saving in case of pre-stressing the rigid unit is achieved due to reduction of the girder cross section. The metal consumption per a column increases by $3 \%$ on average; however, the total metal consumption per a frame is reduced by $7 \%$

TABLE 1 Structural Factors

\begin{tabular}{|c|c|c|c|}
\hline \multirow{2}{*}{$\begin{array}{l}\text { Beam-to-column connection } \\
\text { design }\end{array}$} & \multicolumn{3}{|c|}{ Element type } \\
\hline & Girder & Column & $\begin{array}{l}\text { Frame in } \\
\text { whole }\end{array}$ \\
\hline 1 design - unit on plates & 1,13 & 1,19 & 1,15 \\
\hline 2 design - rigid flange unit & 1,17 & 1,19 & 1,165 \\
\hline $\begin{array}{l}3 \text { design - suggested } \\
\text { structural design }\end{array}$ & $\begin{array}{c}1,29 \\
\text { (inclusive of } \\
\text { ties) }\end{array}$ & 1,19 & 1,215 \\
\hline
\end{tabular}

TABLE 2 Tie Stress For The Frame Pitch Of $3 \mathrm{M}$

\begin{tabular}{|c|c|c|c|c|c|c|}
\hline Load type & \multicolumn{7}{|c|}{ Span, m } \\
\cline { 2 - 7 } & 3 & 4 & 5 & 6 & 9 & 12 \\
\hline $\begin{array}{c}\text { Pre-stressing load, } \\
\text { kN }\end{array}$ & 88,3 & 117,7 & 147,2 & 235,5 & 441,5 & 735,8 \\
\hline $\begin{array}{c}\text { Tensile load by } \\
\text { action of } \\
\text { permanent and } \\
\text { effective loads, } \mathrm{kN}\end{array}$ & 8,8 & 14,7 & 20,6 & 32,4 & 76,5 & 141,3 \\
\hline
\end{tabular}

The tie pre-stressing loads, tensile loads in a tie upon action of permanent and effective loads are presented in the Table 2, the figures in this table are presented for the frame 
pitch of $3 \mathrm{~m}$. The tie length makes $1 / 6$ of the frame span. The compression forces in a tie, i.e. loss of pre-stressing caused by the loads opposite in sign made $8.83-11.77 \mathrm{kN}$ for all spans and the pitch of $3 \mathrm{~m}$. By loading the frame with wind load the forces in ties have opposite signs and equal to $0-14.72 \mathrm{kN}$ at the pitch of $3 \mathrm{~m}$ and all spans, the stress is reduced with increase in the floor height.

The area where it is worth using pre-stressing (shaded areas in the Fig. 5) for frames with a pitch of 3, 4, $5 \mathrm{~m}$ - spans of $5 \mathrm{~m}$, for frames with a pitch of $6,7,8,9$ - for spans from $4 \mathrm{~m}$.

In the examples being considered the metal saving per a building frame made $7 \%$ on the average. The metal saving makes $10-15 \%$ with increase in the number of spans.

\section{CONCLUSION}

Thus, on the basis of studies performed the conclusion may be drawn that the suggested pre-stressing method features the following area of application [21].

It is not worth using the suggested pre-stressing method in single-storey single-span frames. In such buildings the area of application is restricted by buildings up to $4.8 \mathrm{~m}$ high with the spans of $18,24 \mathrm{~m}$ and more. The relative stiffness ratio for most of actual single-span single-story buildings is $\mathrm{k}>0.67$, upon such ration the condition (3) cannot be fulfilled. In single-story frames with 2 and more spans it makes sense to use the suggested girder pre-stressing method above the medium columns only whereby the issue of the roof design by tie placement arises in all single-story buildings.

In multi-storied frames the condition (3) is fulfilled for the range of the relative stiffness ratio $0.1<\mathrm{k}<0.5$ for real objects, i.e. the use of the suggested pre-stressing method is viable. Trial design and comparison of the metal consumption by a frame containing different beam-to-column joints confirm this fact. Metal saving per a building frame in case of using prestressing makes $7 \%$ on the average, saving increases up to 10 $-15 \%$ with increase in the span number. For frames with a pitch of $3-5 \mathrm{~m}$ the suggested pre-stressing method may be used for spans of $5 \mathrm{~m}$ and more meters, for frame pitch of 6 - 9 $\mathrm{m}$ - for spans of 4 and more meters. The area of pre-stressing application in multi-storied frames is restricted by their height and intensity of horizontal load affecting the building frame. In single-span multi-storied frames it makes sense to use prestressing if the number of floors does not exceed 15, in double-span - 25 - 30 floors, upon 3 and more spans - up to 50 floors. In higher buildings the suggested pre-stressing method is advised for use at the upper stories only.

The suggested pre-stressing method can be used for reconstruction and reinforcement of all the above-mentioned frames as well as upon increase in vertical load on the relevant girders.

\section{REFERENCES}

[1] Series 2.440-2. Joints of steel structures of industrial facilities. Issue 1 . Hinged joints of beam framing and framed joints of junctions between girder and column. CNIIProjectstalkonstruktsiya, GPI Lenprojectstalkonstruktsiya, VNIPI Promstalkonstruktsiya. M., 1989.
[2] Series 2.440-2. Joints of steel structures of industrial facilities. Issue 7. Bolted flange framed joints of beams with steel building frame columns. NIPIPromstalkonstruktsiya. M., 1994.

[3] Pavlov, A.B. Fundamentals of design of structural steel works for building frames with allowance for actual bending stiffness and joint strength [Text]: Abstract of thesis for the degree of the $\mathrm{PhD}$ of Engineering Sciences: 05.23.01. / A.B. Pavlov. - Moscow, 1996. - 46 p.

[4] Troitsky, P.N., Levitansky, I.V. Support joints of simply supported beams on vertical plates welded to the beam flange (UNS joints) [Text] / P.N. Troitsky, I.V. Levitansky // CNIIPSK. - M., Stroyizdat - 1970. - № 4.

[5] Troitsky, P.N., Levitansky, I.V. Investigation of the actual behavior of the welded framed attachment assembly and guidelines for designing thereof [Text] / Troitsky, P.N., Levitansky, I.V. // CNIIPSK. - M., Materials about metal works - № $19-1977$.

[6] Jaswant N. Arlekar, C. V. R. Murty. Improved truss model for design of welded steel moment-resisting frame connections / Journal of structural engineering. March 2004.

[7] S. O. Degertekin, M. S. Hayalioglu. Design of non-linear semi-rigid steel frames with semi-rigid column bases / Electronic journal of structural engineering, $4-2004$.

[8] Guochang Li, Hongping Yu, Chen Fang. Perfomance study on T-sub connected semi-rigid joint between rectangular tubular columns and $\mathrm{H}$ shaped steel beams / Frontiers of Structural and Civil Engineering. September 2013.

[9] C. Fang, B. A. Izzuddin, A. Y. Elghazouli, D. A. Nethercot. Modeling of semi-rigid beam to column steel joint under exreme loading / Frontiers of Structural and Civil Engineering. September 2013.

[10] SNiP II-23-81*. Part II. Design standards. Chapter 23 Steel works: approved by the USSR State Committee for Construction 14.08.81: instead of SNiP II-B.3-72 .- M., CITP, 1990. - 96 p.

[11] SP 16.13330.2011. Steel works. Revised edition of SNiP II-23-81*. - M, Minregion Rossii, 2011. - 171 p.

[12] EN 1993-1-1-2009. Eurocode 3. Steel works design. Part 1-1. General rules and regulations for buildings. - Minsk, Ministry for Construction and Architecture of the Republic of Belarus, 2009. - $85 \mathrm{p}$.

[13] Dobrachev, V.M, Vershinin, D.S. Rigid joint coupling beam to column in a steel-framed a multistory building. Utility model patent № 146862 , published 20.10.2014 Bulletin 29.

[14] Dobrachev, V.M, Vershinin, D.S., Vasyta B. N. Enhanced joint coupling beams to column in the steel frame a multistory building. Utility model patent № 153967, published 10.08.2015 Bulletin 22 .

[15] Vershinin, D.S. Rigid joint coupling beam to column in a multistory building steel frame with high load-bearing capacity of the column wall. Utility model patent № 156946, published 20.11.2015 Bulletin 32 .

[16] Dobrachev, V.M, Vershinin, D.S. Frame joint bearing beams on the middle column in the steel frame a multistory building. Utility model patent № 150481, published 20.02.2015 Bulletin 5.

[17] Dobrachev, V.M, Vershinin, D.S. Composite steel and concrete bearing joint of beams in the middle column in the steel-framed a multistory building. Utility model patent № 153644, published 27.07.2015 Bulletin 21.

[18] Kuznetsov, N.V. Practical design of frames and frameworks. Publishing House 'Budivelnyk', Kiev. 1970. - 215 p.

[19] Series 11-2537 KM. Steel works of the 'Kansk' type frames of singlestorey industrial buildings with the use of supporting (carrying) frames from rolled broad-flanged and welded H-beams with the pitch of $12 \mathrm{~m}$. TSNIIProjectstalkonstruktsiya, M. 1987.

[20] Guidelines for design, production and assembly of flange joints of structural steel works. Head office for scientific and engineering information, M. 1989. - 52 p.

[21] Dobrachev, V.M, Vershinin, D.S. New frame-parts engineering solutions for the steel frame of the building / Proceedings of the higher education institutions. Building. - Novosibirsk, - number $7-2015$. 126 